\title{
Problems in Modeling and Forecasting Climate Change: CMIP5 General Circulation Models versus a Semi-Empirical Model Based on Natural Oscillations
}

\author{
Nicola Scafetta \\ Meteorological Observatory, Department of Earth Sciences, Environment and Georesources, \\ University of Naples Federico II, Largo S. Marcellino, 10 - 80138 Naples, Italy \\ Email: nicola.scafetta@unina.it
}

\begin{abstract}
Since 1850 the global surface temperature has warmed by about $0.9^{\circ} \mathrm{C}$. The CMIP 5 computer climate models adopted by the IPCC have projected that the global surface temperature could rise by $2-5{ }^{\circ} \mathrm{C}$ from 2000 to 2100 for anthropogenic reasons. These projections are currently used to justify expensive mitigation policies to reduce the emission of anthropogenic greenhouse gases such as $\mathrm{CO}_{2}$. However, recent scientific research has pointed out that the IPCC climate models fail to properly reconstruct the natural variability of the climate. Indeed, advanced techniques of analysis have revealed that the natural variability of the climate is made of several oscillations spanning from the decadal to the millennial scales (e.g. with periods of about 9.1, 10.4, 20, 60, 115, 1000 years and others). These oscillations likely have an astronomical origin. The same considerations yield to the conclusion that the IPCC climate models severely overestimate the anthropogenic climatic warming by about two times. Herein I demonstrate a number of failures of the IPCC models and I propose a semi-empirical climate model able to reconstruct the natural climatic variability since Medieval times. I show that this model projects a very moderate warming until 2040 and a warming less than $2{ }^{\circ} \mathrm{C}$ from 2000 to 2100 using the same anthropogenic emission scenarios used by the CMIP5 models. This result suggests that climatic adaptation policies, which are less expensive than the mitigation ones, could be sufficient to address most of the consequences of a climatic change during the $21^{\text {st }}$ century. Finally, I show that a temperature forecast made in 2011 by Scafetta (Ref. 25) based on harmonic oscillations has well agreed with the global surface temperature data up to August 2016.
\end{abstract}

Keywords: Global warming, Climate models, Natural versus anthropogenic variability, Natural oscillation, Solar and astronomical forcings.

\section{INTRODUCTION}

Since 1900 the global surface temperature of the Earth has warmed by about $0.9^{\circ} \mathrm{C}$ and since the $1970 \mathrm{~s}$ by about $0.5^{\circ} \mathrm{C}$ : see Figure 1. This warming has occurred during a significant increase of atmospheric concentration of some greenhouse gases (GHG), especially $\mathrm{CO}_{2}$ and $\mathrm{CH}_{4}$, known to have been mainly induced by anthropogenic fossil fuel burning. According to an interpretation of the observed warming based on analytic climate models - e.g. those of the Coupled Model Intercomparison Project Phase 5 General Circulation Models (CMIP5 GSMs) [1] - anthropogenic emissions should be responsible for more than the $90 \%$ of the global warming observed since 1900 and virtually $100 \%$ of that observed since 1970.

The same climate models have been also used to obtain projections for the $21^{\text {st }}$ century global surface temperature warming according to alternative GHG emission scenarios. The conclusion was that the average surface temperature of our planet could rise by $2-5^{\circ} \mathrm{C}$ from 2000 to 2100: see Figure 1. Such a projected warming could potentially endanger humanity mostly because of sea level rise and a significant reduction of fresh water supply in many sensitive locations of the Earth [2]. These projections are used to justify the necessity of implementing expensive mitigation policies in an attempt to severely reduce the emission of anthropogenic greenhouse gases.

The above interpretation of the observed climate change since 1900 is known as the Anthropogenic Global Warming Theory (AGWT). Since 2001 this theory has been widely advocated mostly by the Intergovernmental Panel on Climate Change (IPCC) [1]. This organization is the leading body for the assessment of climate change established by the United Nations Environment Programme (UNEP) and the World Meteorological Organization (WMO).

However, recent scientific research has pointed out that the analytic climate models fail to properly reconstruct the natural variability of the climate. One of the implications is that they have significantly overestimated the climatic effects of the anthropogenic emissions. A survey of this scientific literature was collected for example in Ref. [3]. 
In this short review I will briefly summarize some of the main reasons why the AGWT should be questioned. In addition, I will show that an alternative interpretation of climate change based on the evidences that a significant part of it is due to specific natural oscillations is possible. A modeling based on such interpretation agrees better with the climatic comprehensive picture deduced from the data [4].

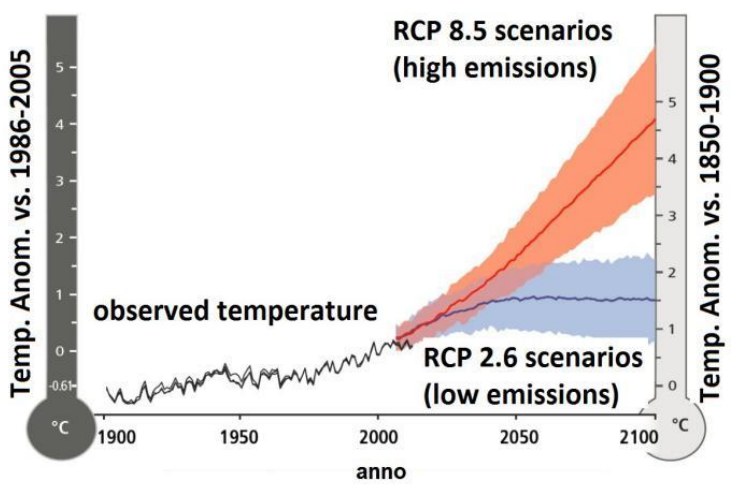

Figure 1. Observed global surface temperature variation and two alternative climatic projections [1]

\section{THE AGWT GCMS AND THEIR FAILURES}

The analytic modeling of the climate relies on a complex set of coupled differential equations describing the circulations of the atmosphere and of the ocean. This system is also assumed to be under the influence of a set of external radiative forcings functions [1]. If the forcing functions were constant the climate system would at most fluctuate around a mean value similarly to a correlated red noise. Therefore, a time change of the forcing functions is required for obtain climate change.

The typical forcing functions used in the climate models are those deduced from the changes of atmospheric $\mathrm{GHG}$ concentrations such as $\mathrm{CO}_{2}, \mathrm{CH}_{4}$ etc., of atmospheric aerosol concentration, of land use change, of vulcanic aerosol, of total solar irradiance and others. Figure 2 summarizes these functions. The claim is that with the exception of the solar and volcanic forcings, all other forcings have an anthropogenic origin. Note that water vapor $\left(\mathrm{H}_{2} \mathrm{O}\right)$ is the most important of the GHGs but it is not included among the models' forcings because it is assumed to be a feedback of the system whose evolution is directly calculated by the thermodynamic equations of the models.

However, determining the radiative forcing functions of the climate is not sufficient. Even assuming that no other forcing functions exist, the most important climatic parameter is the climate sensitivity to radiative forcing. The analytic climate models such as the CMIP5 GCMs estimate that if the $\mathrm{CO}_{2}$ atmospheric concentration doubles its greenhouse effect comprehensive of all feedbacks could cause the climate system to warm at the equilibrium by about $3{ }^{\circ} \mathrm{C}$ within a range spanning between 1.5 and $4.5{ }^{\circ} \mathrm{C}$.

First, it should be observed that the error-bar of the above estimate is very large $(+/-50 \%)$ : the same radiative forcing could cause a warming ranging from a given minimum value to a three times larger value. This error is mostly due to the poor ability of the models in reproducing the various feedbacks including the modeling of the water vapor and the cloud system. In addition, numerous studies have pointed out that the climate sensitivity calculated by the models appears overestimated. A more likely range for the climate sensitivity is about half of the above one: that is, the real climate sensitivity should span between 0.75 and $2.25{ }^{\circ} \mathrm{C}$ with an average of $1.5{ }^{\circ} \mathrm{C}$. Figure 3 compares a number of these climate sensitivity estimates.

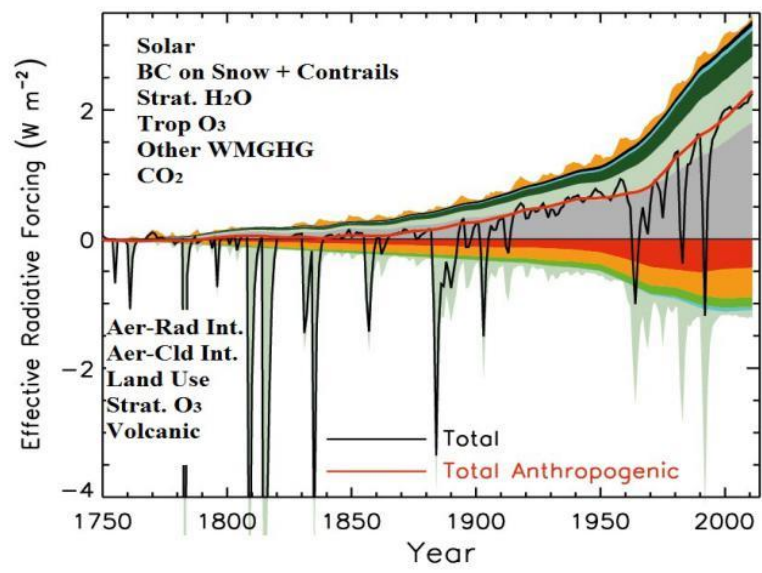

Figure 2. Typical radiative forcing functions used in the analytic general circulation models [1]

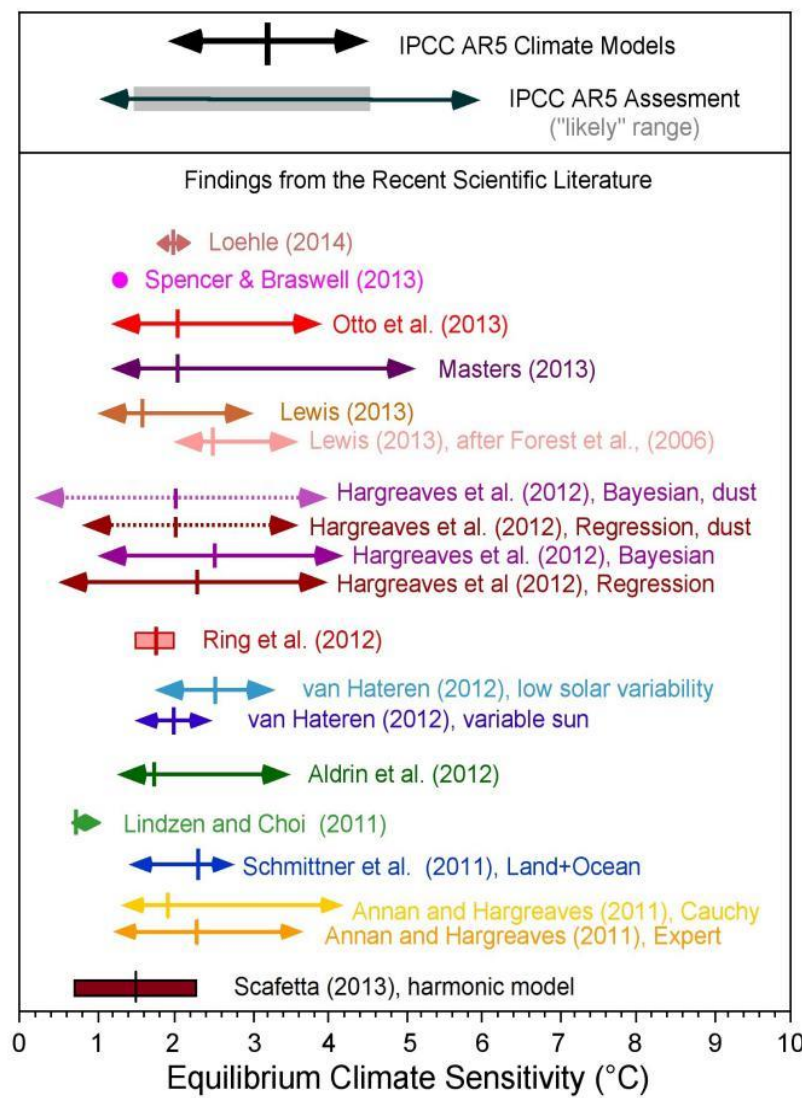

Figure 3. Comparison among estimates of the climate sensitivity to the radiative forcing induced by a doubling of atmospheric $\mathrm{CO}_{2}$ concentration $[1,2,4,5]$

The fact that the real climate sensitivity to radiative forcing could be about half of what calculated by the analytic climate models trusted by the IPCC to interpret the $20^{\text {th }}$ century warming and to project future climate changes yields serious consequences. Evidently, the reliability of those models should be questioned and, consequently, the economical 
policies suggested by the AGWT to address the climate change issue for the $21^{\text {st }}$ century should be changed.

Thus, the performance of the available climate models needs to be carefully valuated because if the climate models do not reproduce well past climate changes they cannot be trusted in their projections. It is possible that some required forcings are still ignored and/or that the equations used to model the climate might be still too simplistic.

\section{EVIDENCES FOR LARGE NATURAL CLIMATE OSCILLATIONS NOT REPRODUCED BY THE GCMS}

There are several empirical evidences that the GCMs used to support the AGWT macroscopically fail in reproducing the observed climatic variations at multiple time scales. Let us discuss a few main cases.

Shakun et al. [6] showed that global warming preceded by increasing carbon dioxide concentrations during the last deglaciation. Moreover, temperature reconstructions of the Holocene [6,7] suggest that after the Holocene maximum (8000 - 9000 years ago) the global surface temperature cooled by about $1.0-0.5^{\circ} \mathrm{C}$ as it would be expected by the Milankovitch theory. However, climate models, by following the observed increase of $\mathrm{CO}_{2}$ concentration measured during the same period, have hindcast a global surface temperature warming by about $0.5^{\circ} \mathrm{C}$ to $1^{\circ} \mathrm{C}$ over the last 11,000 years: see Figure 4 [8]. In addition, Figure 5 compares the Holocene temperature evolution as estimated in the GIPS2 record (Greenland) [9] against the $\mathrm{CO}_{2}$ record, where the difference in the trend of the two records during the last 4000 years is also evident.

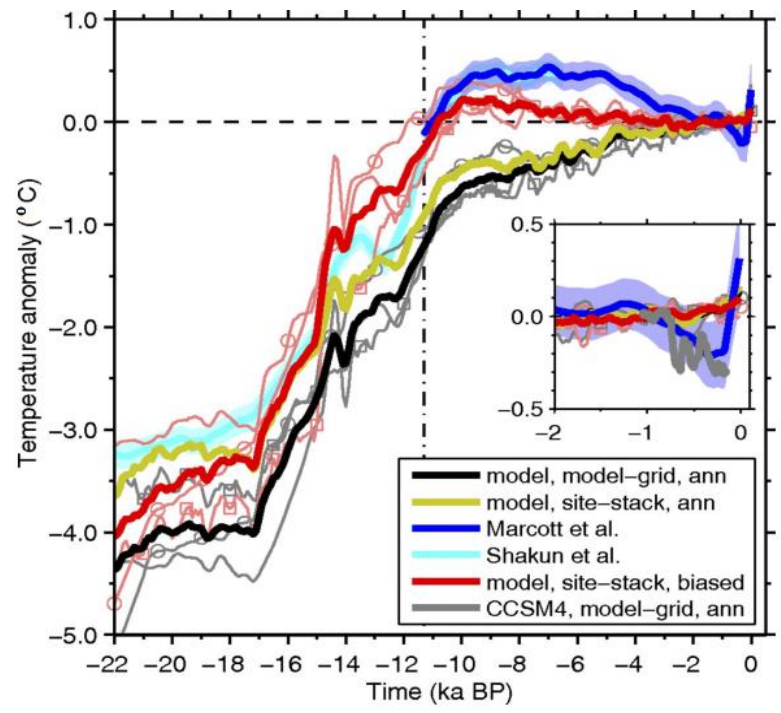

Figure 4. Comparison between Holocene temperature records (red and blue) and climate model predictions (green, black and gray). From Liu et al. [8]

Figure 5 also highlights that the temperature record of the Holocene has been characterized by a large quasi millennial oscillation not reproduced by the $\mathrm{CO}_{2}$ record. In fact, the models also fail to reconstruct this large oscillation that has been responsible for the well-known Roman, Medieval and Current warm periods and the Dark Age and Little Ice Age cold periods [4]. Indeed, this large millennial climatic oscillation is far better correlated with solar activity and cosmic ray flux variation indexes such as ${ }^{14} \mathrm{C}$ and ${ }^{10} \mathrm{Be}$ isotope records $[10,11,12,13]$ than with $\mathrm{CO}_{2}$ or other GHGs records [4]: see Figure 6.
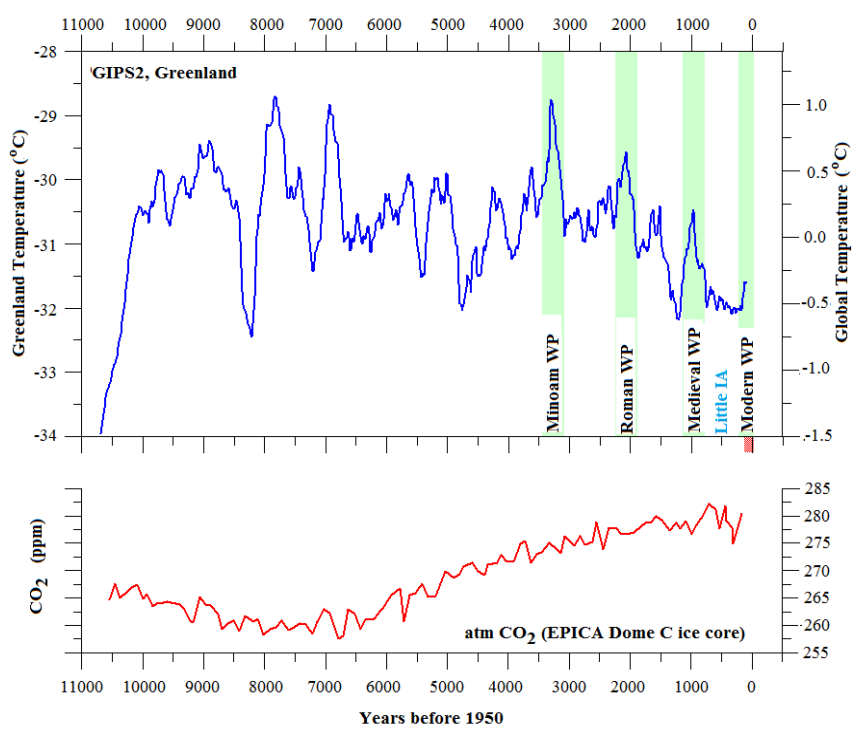

Figure 5. Comparison between Holocene temperature record from GIPS2 (upper) [9] and the $\mathrm{CO}_{2}$ record [8]

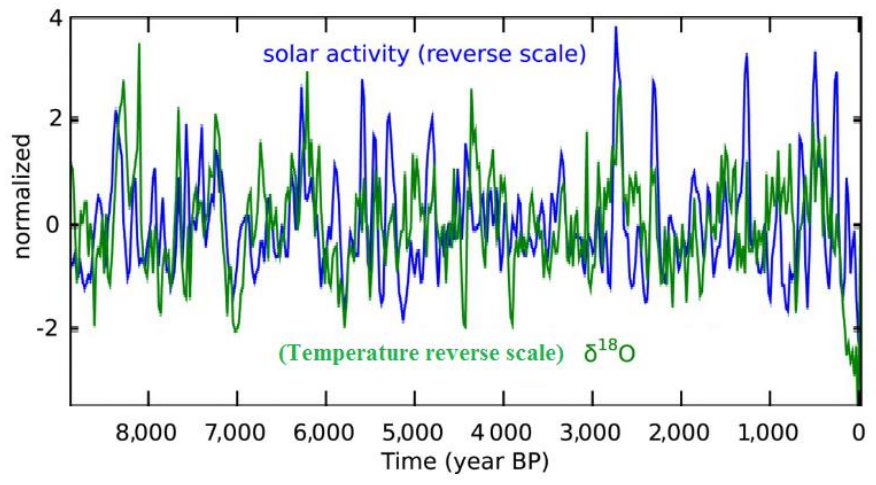

Figure 6. Comparison between a solar activity record in blue based on cosmic ray flux and the $\delta^{18} \mathrm{O}$ record from Dongge cave, China, in green representing changes of the Asian climate. From Steinhilber et al. (2012) [12]

Indeed, the main reason why a significant portion of the scientific community is still accepting the reliability of the current climate models and, therefore, of the AGWT, which derives from them, is because the scientific development on this topic during the last decade has not been correctly acknowledged. Today it is known that significant components of the natural climate variability on both the long and short time scales have not been reproduced by the models.

In fact, since the year 2000 the available climate models based on radiative forcings have been considered sufficiently validated because they were proven to be able to approximately fit specific surface temperature reconstructions claiming that the temperature has remained approximately constant from 1000 A.D. to 1900 A.D. and raised abruptly since 1900 [14]. These specific temperature reconstructions of the Norther Hemisphere [15] are known in the scientific literature as the Hockey Stick temperature reconstructions: see the upper panel of Figure 7. The hockey stick pattern is well interpreted by the current AGWT models because these models predict that the natural climate variability is 
significantly smaller than what anthropogenic forcing, in primis $\mathrm{CO}_{2}$, could have done during the last century [1].

However, since 2005 alternative reconstructions of the Norther Hemisphere temperature have been proposed $[16,17,18]$ : see the panels A-D of Figure 7 . These recent temperature reconstructions have demonstrated that the climate has been characterized by a large millennial oscillation during the last 2000 years. The natural climate variability manifested in these records is 3-4 times larger than that shown in the hockey stick temperature reconstructions. Thus, the most recent temperature reconstructions demonstrate the importance of modeling the natural climate variability to correctly interpret climate change.

In fact, the warming observed since 1900 started, indeed, in the $18^{\text {th }}$ century, that is, since the end of the Little Ice Age. This happened well before the anthropogenic GHG emissions could have had any significant impact on the climate. Thus, the modern warming period could also be the result of a natural warming trend due to the quasi millennial oscillation that both climate and solar records manifest quite clearly during the Holocene.

Figure 7 compares the Hockey Stick temperature reconstruction $[14,15]$ versus novel temperature reconstructions of the Norther Hemisphere [16,17,18,19]. Here it is seen that while the Hockey Stick temperature reconstruction predict a cooling of just about $0.2{ }^{\circ} \mathrm{C}$, or less, from the Medieval Warm Period to the Little Ice Age of the $16-19^{\text {th }}$ centuries, the more recent temperature reconstructions show a variability during the same period of about $0.6-0.7{ }^{\circ} \mathrm{C}$ in several regions of the Earth.

The large climatic variability observed since the medieval times can be correctly interpreted only if the climatic effects of solar variability on the climate have been severely underestimated by the climate models by a 3 to 6 factor and simultaneously the climatic effect of the radiative forcings, which include the $\mathrm{CO}_{2}$ forcing, has been overestimated by at least a factor of 2 by the same models [4].

There are additional evidences that the climate models supporting the AGWT fail to properly reconstruct the climatic features at the decadal and multidecadal scale. Let us discuss three cases.

A) It has been observed that for the last decades climate models predict a hot-spot, that is, a significant warming of a band of the upper troposphere $10 \mathrm{~km}$ over the tropics and the equator. The presence of this hot-spot is quite important because it would indicate that the water-vapor feedback to radiative forcing would be correctly reproduced by the models. However, this predicted hot-spot has never been not found in the tropospheric temperature records [20,21]. This could only suggesting that both the temperature records obtained with satellite measures and balloons have been poorly handled or that the models severely fail to properly simulate the water-vapor feedback. In the latter case, the flaw of the models would be fatal because the water-vapor feedback is the most important among the climate feedbacks. Without a strong feedback response from water vapor the models would only predict a moderate climate sensitivity to radiative forcing of about $1.2^{\circ} \mathrm{C}$ for $\mathrm{CO}_{2}$ doubling instead of about $3{ }^{\circ} \mathrm{C}$. Figure 8 compares the observed temperature trend in the troposphere versus the climate model predictions: from Ref. [21]. The difference between the two record sets is evident.
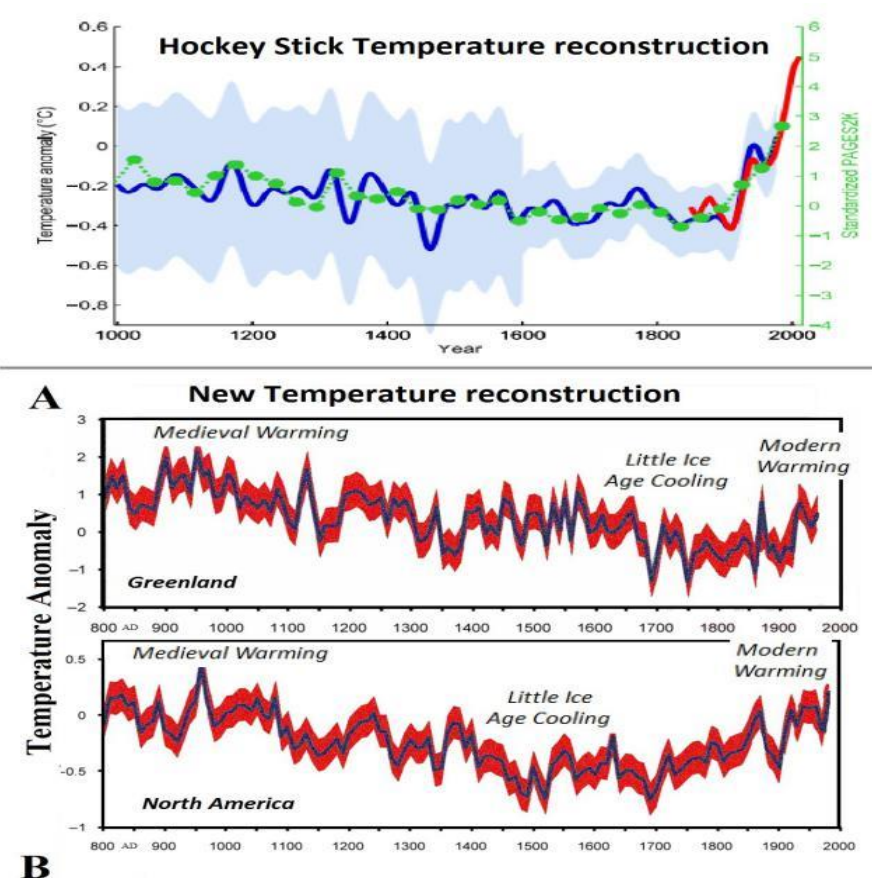

B
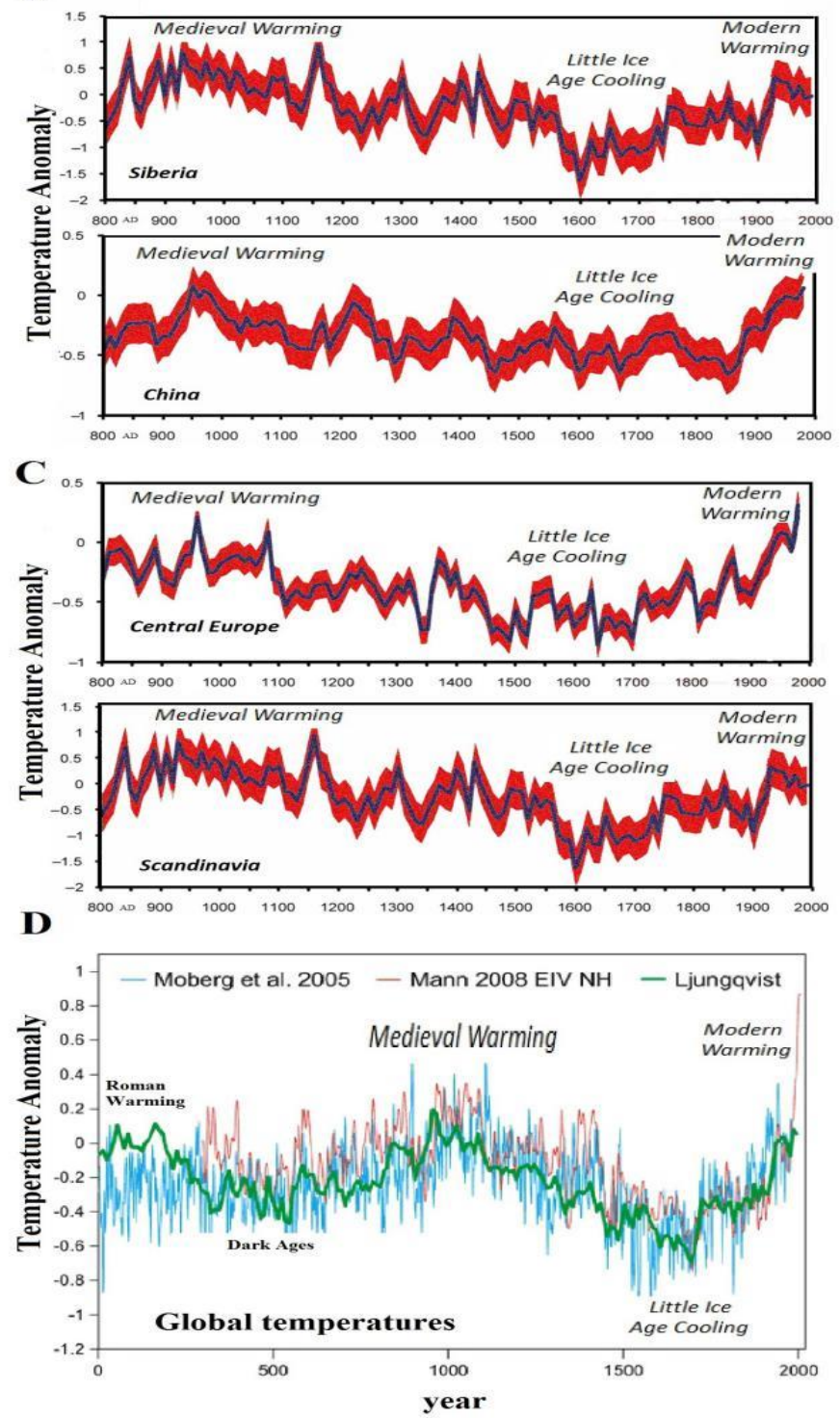

Figure 7. Comparison between the Hockey Stick temperature reconstruction $[14,15]$ (top panel) and novel temperature reconstructions of the Norther Hemisphere (A,B,C,D lower panels) $[16,17,18,19]$. 


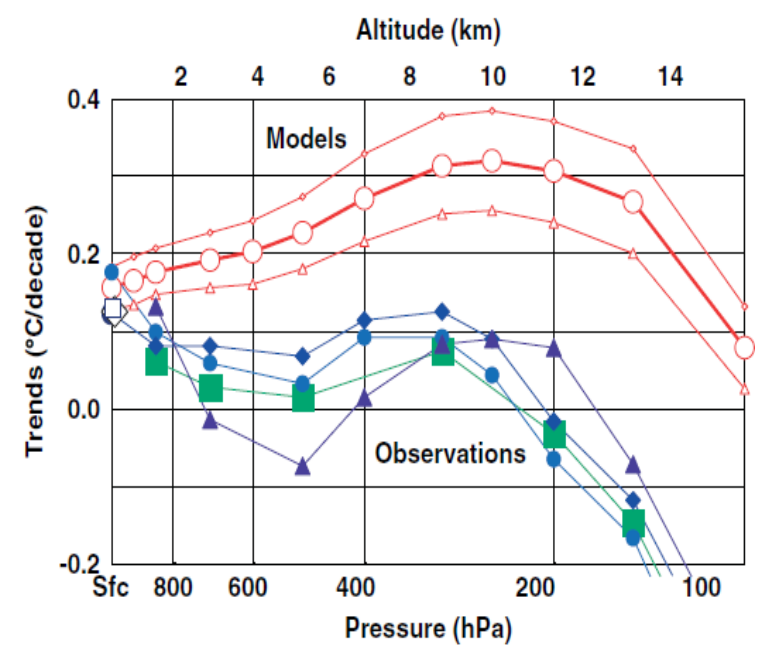

Figure 8. Comparison between observed temperature trend in the troposphere (green-blue) versus the climate model predictions (red). From Ref. [21].

B) Scafetta and Mazzarella [22] studied the Arctic and Antarctic sea-ice area index records versus measured and modeled temperature data since 1980 and demonstrated that while the Arctic has been warming approximately as predicted by the climate models, the Antarctic has been cooling. The cooling trend observed around Antarctica significantly contradicts the warming predicted by the CMIP5 GCMs during the same period and the same region.

C) A careful analysis of the global surface temperature records, which is available since 1850 [23], has established that these records are characterized by a warming secular trend plus a set of major oscillations with periods of about $9.1,10.4,20$, and 60 years $[4,24]$. One of the effects of these oscillations have resulted in a quasi steady temperature trend from 2000 to 2015. A detailed analysis of these oscillations has concluded that none of the CMIP5 GCMs is able to model them since 1850 [4,25].

There are numerous important consequences that can be derived from the existence of large natural decadal and multidecadal oscillations, which are not reproduced by the climate models. For example, the global surface temperature has nearly remained stationary from 2000 to 2016 (the socalled hiatus). The interpretation of this finding is simple once it is noted that the 60-year natural oscillation has been in its cooling phase and has compensated the anthropogenic warming occurred during the same period. On the contrary, the GCMs have on average predicted a $2{ }^{\circ} \mathrm{C} /$ century warming trend during the same period.

To show the incongruity between modeled and measures records since 2000, Figure 9 compares temperature observations versus the CMIP5 model projections relative to 1986-2005 period. The divergence since 2000 is quite evident. The black lines represent an average among temperature observational datasets (HadCRUT4.4, Cowtan \& Way, NASA GISTEMP, NOAA NCDC, BEST).

All above evidences suggest that the climate system is more complicated than what the current climate models assume. The solar effect, which includes a variety of luminosity, electromagnetic and particle phenomena, appears significantly underestimated, and the effects of the purely radiative forcings, which are the only ones taken into consideration by the CMIP5 climate models, appear significantly overestimated.

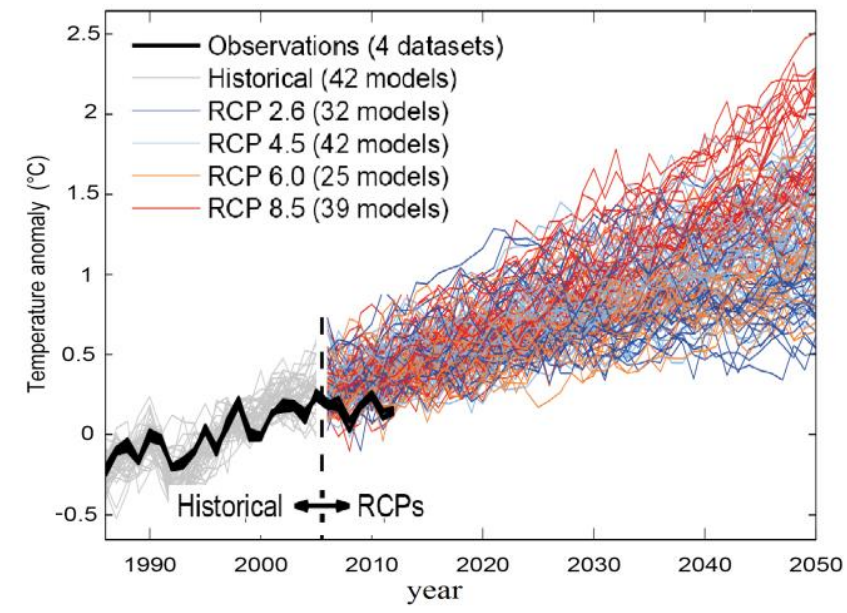

Figure 9. IPCC AR5 Figure 11.25a [1], showing observations and the CMIP5 model projections relative to 1986-2005. The

black lines represent an average among temperature observational datasets (HadCRUT4.4, Cowtan \& Way, NASA GISTEMP, NOAA NCDC, BEST)

\section{A SEMI-EMPIRICAL CLIMATE MODEL BASED ON NATURAL OSCILLATIONS}

As already noted above, harmonic analysis of the global surface temperature records since 1850 have highlighted that these records are characterized by major oscillations with periods of about $9.1,10.4,20$, and 60 years [4, 24]: see Figure 10.

In particular, a large oscillation of about 60 -year is evident in the temperature data: the 30-year periods 1850-1880, 19191940 and 1970-2000 were characterized by an evident warming, while the periods 1980-1910, 1940-1970 were characterized by an evident cooling. Since 2000 the global surface temperature has been nearly stationary even though the year 2015 has be particularly warmer than the previous years.

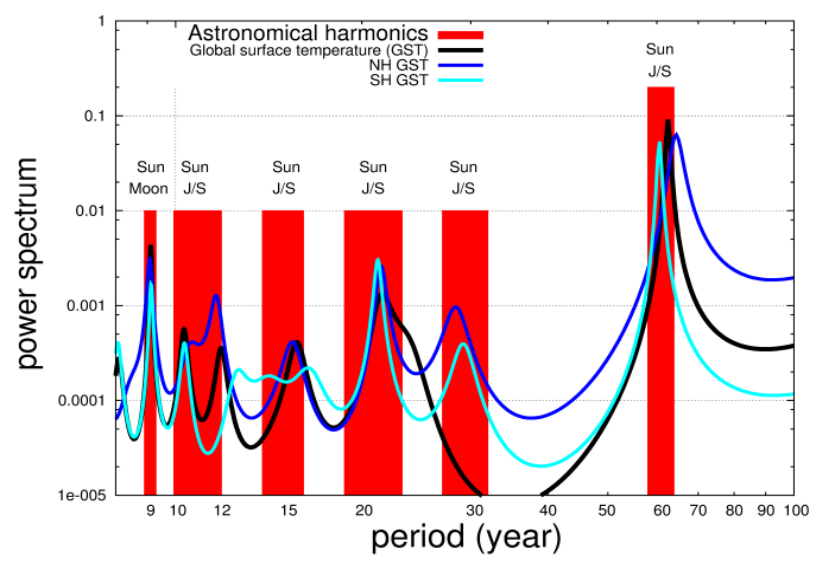

Figure 10. Spectral analysis of the global surface temperature records. From Ref. [4]. The red area refers to known astronomical oscillation of the solar system induces by the sun, the Moon, Jupiter and Saturn

The existence of 20 and 60-year natural oscillations at the observed phases implies that about $50 \%$ of the warming observed from 1970 to 2000 must have been induced by them. This leaves only the leftover $50 \%$ to anthropogenic forcings, not neatly $100 \%$ as claimed by the CMIP5 GCMs trusted by 
the IPCC [1]. Again, this observation suggests that the current climate models overestimate by a factor of 2 the warming effect of the radiative forcing, such as that induced by $\mathrm{CO}_{2}$ emission.

That the climate system might be modulated by specific oscillations has been confirmed by a large number of publications: see Ref. [4,24] and their citations. This property suggests that these oscillations are astronomically induced. Indeed, a careful analysis of the gravitational oscillation of the solar system and of the solar-lunar tidal system has concluded that astronomical and climate records share a large number of harmonics [4,24,25,26,27].

Figure 11 shows a comparison between the continuous spectral analysis of the speed of the sun relative to the barycentre of the solar system - which is a good proxy for determining the major gravitational oscillation of the solar system - and of the global surface temperature records [4]. High resolution methodologies have shown that the spectral coherence between the two records has a statistical confidence of $95 \%$ at least for the oscillations with the following periods: $6.6,7.4,14,20$ and 60 years [27].

Figure 11 also shows that the temperature is characterized by a quasi 9.1-year oscillation which is not present in the analyzed solar record. However, this oscillation is clearly a tidal oscillation because this period falls within three solar and lunar tidal periods: the 8.85 lunar perigee cycle, the second harmonic of the 18-year Saros eclipse cycle (about 9 years) and that of the 18.6 lunar nodal cycle (about 9.3 year) [24,28].

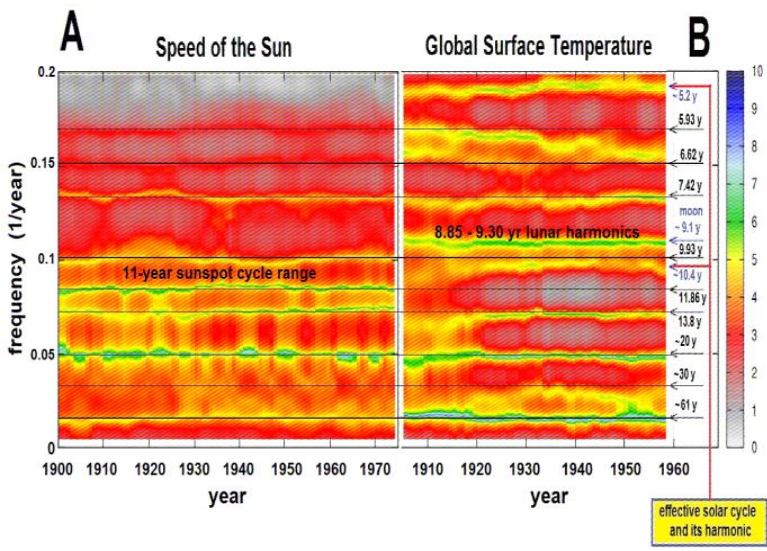

Figure 11. Comparison between the continuous spectral analysis of the speed of the sun relative to the barycentre of the solar system (left) and of the global surface temperature record (right). From Ref. [26]

In addition, the varying temperature oscillation observed between the 10 and 12 year astronomical frequencies is the temperature signature of the sun-spot cycle. In fact, the 11year solar cycle is bounded by the 9.93-year Jupiter-Saturn spring tidal cycle and the 11.86-year Jupiter orbital tidal cycle [29]. Ref. [29] also demonstrates that the combination of the above two planetary tidal oscillations and the 11-year solar cycle produces beats with period of about 115 and 983 years. These long oscillations are synchronous with equivalent oscillations observed in the climate and solar records during the Holocene [29].

I have proposed that the global surface temperature record could be reconstructed from the decadal to the millennial scale using a minimum of 6 harmonics at 9.1, 10.4, 20, 60, 115 and 983 years plus a anthropogenic and volcano contribution that can be evaluated from the CMIP5 GCM outputs reduced by half because, as discussed above, the real climate sensitivity to radiative forcing appears to be about half of what assumed by the current climate models. The figure highlights the better performance of the solar-astronomical semi-empirical model versus the CMIP5 models. This is particularly evident since 2000 , as shown in the inserts. More details about this model and its performance are discussed in Ref. [4].

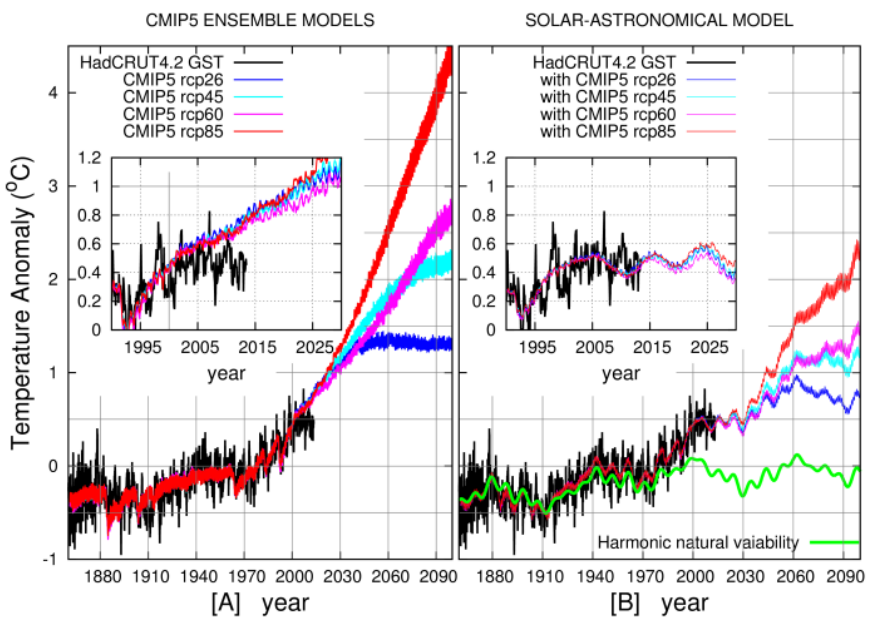

Figure 12 [A] The four CMIP5 ensemble average projections versus the HadCRUT4 GST record (black). [B] The solarastronomical semi-empirical model. From Ref. [4]

\section{CONCLUSION}

Since 1850 the global surface temperature has warmed by about $0.9{ }^{\circ} \mathrm{C}$. This warming has been interpreted using general circulation climate models such as the CMIP5 GCMs [1]. The conclusion deduced from the climatic simulations of these models was that the observed $20^{\text {th }}$ century warming has been almost entirely induced by anthropogenic emission related mostly to fossil fuel burning.

The same computer climate models were then adopted to evaluate climate projections for the $21^{\text {st }}$ century and have concluded that the temperature could rise by more than $2{ }^{\circ} \mathrm{C}$ from 2000 to 2100 for anthropogenic emissions. These projections are currently used to justify the necessity of expensive mitigation policies with the hope to severely reduce the emissions of anthropogenic greenhouse gases.

However, herein I have shown that recent scientific research has pointed out that the IPCC climate models fail to properly reconstruct the natural variability of the climate at multiple scales. On the contrary, advanced techniques of pattern recognition patters have pointed out that the natural variability of the climate appears to be made of several oscillations from the decadal to the millennial scales (e.g. periods of about 9.1, 10.4, 20,60, 115, 1000 years and others). These oscillations were also found to have a likely astronomical origin.

The considerations emerging from these findings yield to the conclusion that the IPCC climate models severely overestimate the anthropogenic climatic warming by about two times. I have finally proposed a semi-empirical climate model calibrated to reconstruct the natural climatic variability since Medieval times. I have shown that this model projects a very moderate warming until 2040 and a warming less than 2 ${ }^{\circ} \mathrm{C}$ from 2000 to 2100 using the same anthropogenic emission scenarios used by the CMIP5 models: see Figure 12. This result suggests that climatic adaptation policies, which are less 
expensive than the mitigation ones, could be sufficient to address most of the consequences of a climatic change during the $21^{\text {st }}$ century. Similarly, fossil fuels, which have contributed significantly to the development of our societies, can still be used to fulfill our energy necessities until equally efficient alternative energy sources could be determined and developed $[30,31]$.

A major scientific conclusion is that the climate is significantly modulated by astronomical oscillation which may not be related to the solar luminosity variation. A possibility is that the cloud system could be directly modulated by the cosmic ray flux, which is modulated by the gravitational and electromagnetic oscillations of the heliosphere $[4,13,26,32]$. This eventuality suggests that the current climate models are not reliable because important climate forcings are still not used.

\section{APPENDIX: A 2011 FORECAST VALIDATION}

In 2011 I prepared a global surface temperature forecast based on a simplified climate model based on four natural oscillations $(9.1,10.4,20$ and 60 year) plus an estimate of a realistic anthropogenic contribution [25]: for example, see Refs. [33,34,35] referring to the 60-year cycle. Figure 13 compares my 2011 forecast (red curve) against the global surface temperature record I used in 2011 (HadCUT3, blue curve) and a modern global surface temperature record updated at June/2016 (RSS MSU record, black line, http://www.remss.com/measurements/upper-air-temperature). The RSS MSU record, which is a global surface temperature estimate using satellite measurements, was linearly rescaled to fit the original HadCUT3 global surface temperature record for optimal comparison. Other global temperature reconstructions perform similarly. Note that the HadCUT3 has been dismissed in 2014. Figure 13 also shows in green a schematic representation of the IPCC GCMs prediction since 2000 [25].

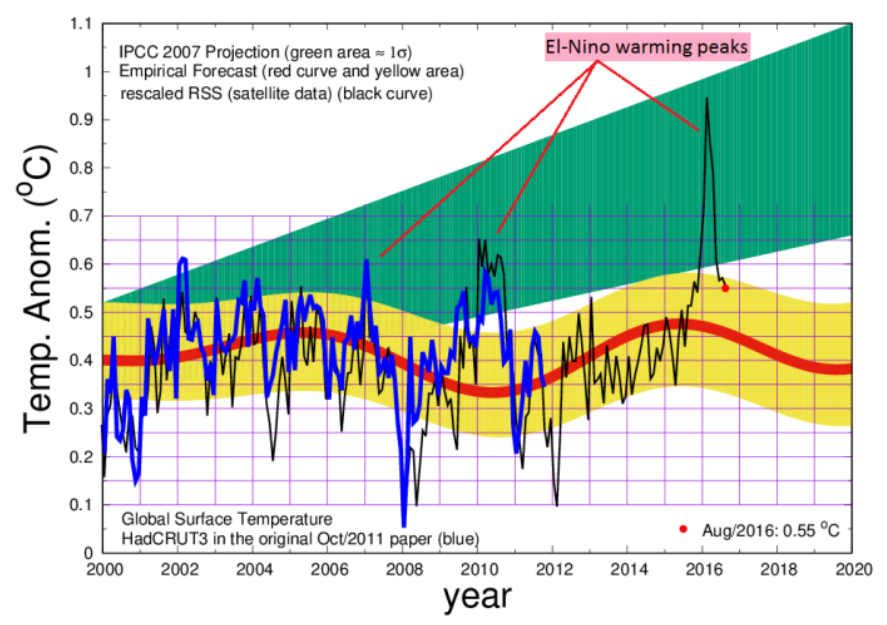

Figure 13. Comparison of the forecast (red-yellow curve) made in Scafetta (2011) [25] against (1) the temperature record used in 2011 (HadCRUT3, blue curve), (2) the IPCC climate model projections since 2000 (green area), (3) a recent global temperature record (RSS MSU record, black line, linearly re-scaled to match the HadCRUT3 from 1979 to 2014). The temperature record has followed Scafetta's forecast better than the IPCC ones. In 2015-2016 there was a strong El-Nino Pacific Ocean natural warming that caused the observed temperature peak
Figure 13 clearly indicates that since 2000 and also since 2012 (that is, for the real 5-year forecast period) the global surface temperature record has followed my 2011 climatic prediction significantly better than the prediction based on the climate models used by the IPCC, which are given by the green area [1]. This fact is not questioned also by the temperature peak reached between the end of 2015 and the beginning of 2016. This temperature peak was simply due to a strong El-Nino warming effect, which since then has been rapidly vanishing, as Figure 13 shows. Evidently, this 20152016 temperature peak has nothing to do with anthropocentric forcing because it was due to the well-know ENSO natural oscillation of the Pacific Ocean. The climate model proposed in Ref. [25] was not supposed to predict the ENSO oscillations because these oscillations have a time scale of a few years, which is significantly smaller than the decadal to the secular time scales modeled by the model.

\section{REFERENCES}

[1] The Intergovernmental Panel on Climate Change (IPCC), 2013. Climate Change 2013: The Physical Science Basis. (eds Stocker, T. F. et. al) (Cambridge Univ. Press, 2013). [http://www.ipcc.ch/]

[2] Rockstrom J., et al., "A safe operating space for humanity," Nature, vol. 461, pp. 472-475, 2009. DOI: 10.1038/461472a.

[3] Idso, D. C., Carter, R. M., Singer, S. F., Karnick, S. T. and Bast, D. C., "Climate change reconsidered II: Physical science," The Heartland Institute (September 17, 2013). http://www.climatechangereconsidered.org/.

[4] Scafetta, N., "Discussion on climate oscillations: CMIP5 general circulation models versus a semiempirical harmonic model based on astronomical cycles." Earth-Science Reviews, vol. 126, pp. 321-357, 2013. DOI: 10.1016/j.earscirev.2013.08.008.

[5] Lewis, N., "An objective bayesian improved approach for applying optimal fingerprint techniques to estimate climate sensitivity," J. Climate, vol. 26, pp. 7414-7429, 2013. DOI: 10.1175/JCLI-D-12-00473.1.

[6] Shakun, J., Clark, P. U., He, F., et al., "Global warming preceded by increasing carbon dioxide concentrations during the last deglaciation." Nature, vol. 484, pp. 4954, 2012. DOI: $10.1038 /$ nature 10915.

[7] Marcott, S.A., Shakun, J.D., Clark, P.U., Mix A.C., “A reconstruction of regional and global temperature for the past 11,300 years," Science, vol. 339, pp. 1198 1201, 2013. DOI: $10.1126 /$ science.1228026.

[8] Liu, Z., Zhu, J., Rosenthal, Y., et al., "The Holocene temperature conundrum," PNAS, vol. 111, pp. E3501E3505, 2014. DOI: 10.1073/pnas.1407229111.

[9] Alley, R.B., 2004, GISP2 Ice Core Temperature and Accumulation Data. IGBP PAGES/World Data Center for Paleoclimatology Data Contribution Series \#2004013. NOAA/NGDC Paleoclimatology Program, Boulder CO, USA.

[10] Bond, G., Kromer, B., Beer, J., Muscheler, R., et al., "Persistent solar influence on North Atlantic climate during the Holocene," Science, vol. 294, pp. 21302136, 2001. DOI: $10.1126 /$ science. 1065680.

[11] Kerr, R. A., "A variable sun paces millennial climate," Science, vol. 294, pp. 1431-1433, 2001. DOI: 10.1126/science.294.5546.1431b. 
[12] Steinhilber, F., Abreu, J. A., Beer, J., et al., “9,400 years of cosmic radiation and solar activity from ice cores and tree rings," PNAS, vol. 109, pp. 5967-5971, 2012. DOI: $10.1073 /$ pnas.1118965109.

[13] Kirkby, J., "Cosmic rays and climate," Surv. Geophys., vol. 28, pp. 333-375, 2007. DOI: $10.1007 / \mathrm{s} 10712-$ 008-9030-6.

[14] Crowley, T.J., "Causes of climate change over the past 1000 years," Science, vol. 289, pp. 270-277, 2000. DOI: $10.1126 /$ science.289.5477.270.

[15] Mann, M. E., Bradley, R. S. and Hughes, M. K., "Northern hemisphere temperatures during the pastmillennium: inferences, uncertainties, and limitations," Geophys. Res. Lett., vol. 26, pp. 759-762, 1999. DOI: $10.1029 / 1999 G L 900070$.

[16] Moberg, A., Sonechkin, D. M., Holmgren, K., et al., "Highly variable Northern Hemisphere temperatures reconstructed from low and high resolution proxy data," Nature, vol. 433, pp. 613-617, 2005. DOI: 10.1038/nature03265.

[17] Mann, M. E., Zhang, Z., Hughes, M. K., et al., "Proxybased reconstructions of hemispheric and global surface temperature variations over the past two millennia," PNAS, vol. 105, pp. 13252-13257, 2008. DOI: $10.1073 /$ pnas.0805721105.

[18] Ljungqvist, F. C., "A new reconstruction of temperature variability in the extra-tropical Northern Hemisphere during the last two millennia," Geogr. Ann. A, vol. 92, pp. 339-351, 2010. DOI: 10.1111/j.1468-0459.2010.00399.x.

[19] Christiansen, B. and Ljungqvist, F. C., "The extratropical Northern Hemisphere temperature in the last two millennia: reconstructions of low-frequency variability," Clim. Past, vol. 8, pp. 765-786, 2012. DOI: $10.5194 / \mathrm{cp}-8-765-2012$.

[20] Christy, J. R., Herman, B. and Pielke, Sr., R, et al., "What do observational datasets say about modeled tropospheric temperature trends since 1979?" Remote Sensing, vol. 2, pp. 2148-2169, 2010. DOI: $10.3390 / \mathrm{rs} 2092148$.

[21] Douglass, D. H., Christy, J. R., Pearson, B. D. and Singer S. F., "A comparison of tropical temperature trends with model predictions," International Journal of Climatology, vol. 28, pp. 1693-1701, 2007. DOI: $\underline{10.1002 / \text { joc. } 1651 \text {. }}$

[22] Scafetta, N. and Mazzarella, A.,"The arctic and antarctic sea-ice area index records versus measured and modeled temperature data," Advances in Meteorology, vol. 2015, Article ID 481834, 8 pages, 2015. DOI: $10.4401 / \mathrm{ag}-6899$.

[23] Morice, C. P., Kennedy, J. J., Rayner, N. A. and Jones, P. D., "Quantifying uncertainties in global and regional temperature change using an ensemble of observational estimates: the HadCRUT4 dataset," J. Geophys. Res., vol. 117, D08101, 2012. DOI: 10.1029/2011JD017187.

[24] Scafetta, N., "Empirical evidence for a celestial origin of the climate oscillations and its implications," $J$.
Atmos. Sol. Terr. Phys., vol. 72, pp. 951-970, 2010. DOI: $10.1016 /$ j.jastp.2010.04.015.

[25] Scafetta, N., "Testing an astronomically based decadalscale empirical harmonic climate model versus the IPCC (2007) general circulation climate models," $J$. Atmos. Sol. Terr. Phys., vol. 80, pp. 124-137, 2012. DOI: $10.1016 /$ j.jastp.2011.12.005.

[26] Scafetta, N., "Discussion on the spectral coherence between planetary, solar and climate oscillations: a reply to some critiques," Astrophysics and Space Science, vol. 354, pp. 275-299, 2014. DOI: 10.1007/s10509-014-2111-8.

[27] Scafetta, N., "High resolution coherence analysis between planetary and climate oscillations," Advances in Space Research, vol. 57, no. 10, pp. 2121-2135, 2016. DOI: 10.1016/j.asr.2016.02.029.

[28] Haigh, I. D., Eliot, M. and Pattiaratchi, C., "Global influences of the 18.61 year nodal cycle and 8.85 year cycle of lunar perigee on high tidal levels," J. of Geophysical Research-Ocean, vol. 116, Art. C06025, 2011. DOI: $10.1029 / 2010 J C 006645$.

[29] Scafetta, N., "Multi-scale harmonic model for solar and climate cyclical variation throughout the Holocene based on Jupiter-Saturn tidal frequencies plus the 11year solar dynamo cycle," J. of Atmospheric and SolarTerrestrial Physics, vol. 80, pp. 296-311, 2012. DOI: 10.1016/j.jastp.2012.02.016.

[30] Parisi, M.L., Maranghi, S., Sinicropi, A., Basosi, R., "Development of dye sensitized solar cells: A life cycle perspective for the environmental and market potential assessment of a renewable energy technology." International Journal of Heat and Technology, vol. 31, pp. 143-148, 2013.

[31] Mirandola, A., Lorenzini, E., "Energy, environment and climate: From the past to the future," International Journal of Heat and Technology, vol. 34, pp. 159-164, 2016. DOI: 10.18280/ijht.340201.

[32] Scafetta, N., Milani, F., Bianchini, A., Ortolani, S., "On the astronomical origin of the Hallstatt oscillation found in radiocarbon and climate records throughout the Holocene." Earth-Science Reviews, vol. 162, pp. 24-43, 2016. DOI: 10.1016/j.earscirev.2016.09.004

[33] Mazzarella, A. and Scafetta, N., "Evidences for a quasi 60-year North Atlantic Oscillation since 1700 and its meaning for global climate change," Theoretical and Applied Climatology, vol. 107, pp. 599-609, 2012. DOI: $10.1007 / \mathrm{s} 00704-011-0499-4$.

[34] Loehle, C. and Scafetta, N., "Climate change attribution using empirical decomposition of climatic data," Open Atmospheric Science Journal, vol. 5, pp. 74-86, 2011. DOI: 10.2174/1874282301105010074.

[35] Manzi, V., Gennari, R., Lugli, S., Roveri, M., Scafetta, N. and Schreiber, B.C., "High-frequency cyclicity in the mediterranean Messinian evaporites: Evidence for solar-lunar climate forcing," Journal of Sedimentary Research, vol. 82, pp. 991-1005, 2012. DOI: 10.2110/jsr.2012.81. 